\title{
Cesium and Strontium Separation Technologies Literature Review
}

\author{
T. A. Todd \\ T. A. Batcheller \\ J. D. Law \\ R. S. Herbst
}

March 2004

Idaho National Engineering and Environmental Laboratory Bechtel BWXT Idaho, LLC 


\section{Cesium and Strontium Separation Technologies Literature Review}

T. A. Todd

T. A. Batcheller

J. D. Law

R. S. Herbst

March 2004

Idaho National Engineering and Environmental Laboratory Idaho Falls, Idaho 83415

Prepared for the

U.S. Department of Energy

Office of Nuclear Energy

Under DOE Idaho Operations Office

Contract DE-AC07-99ID13727 


\title{
Cesium and Strontium Separation Technologies Literature Review
}

\begin{abstract}
1. ABSTRACT
Integral to the Advanced Fuel Cycle Initiative (AFCI) Program's proposed closed nuclear fuel cycle, the fission products cesium and strontium in the dissolved spent nuclear fuel stream are to be separated and managed separately. A comprehensive literature survey is presented to identify cesium and strontium separation technologies that have the highest potential and to focus research and development efforts on these technologies.
\end{abstract}

Removal of these high-heat-emitting fission products reduces the radiation fields in subsequent fuel cycle reprocessing streams and provides a significant short-term $(100 \mathrm{yr})$ heat source reduction in the repository. This, along with separation of actinides, may provide a substantial future improvement in the amount of fuel that could be stored in a geologic repository.

The survey and review of the candidate cesium and strontium separation technologies are presented herein. Because the AFCI program intends to manage cesium and strontium together, technologies that simultaneously separate both elements are of the greatest interest, relative to technologies that separate only one of the two elements.

\section{INTRODUCTION AND BACKGROUND}

Chemical processing of irradiated spent nuclear fuel has been ongoing for half a century [1]. Historically, by far, the most widely used industrial-scale reprocessing schemes begin with aqueous dissolution of the spent fuel and subsequent liquid-liquid extraction to separate the uranium and plutonium from radioactive fission and activation products. Other separation methods, such as ion exchange/extraction chromatography continue to be developed, but are typically used to treat secondary waste streams.

Liquid-liquid extraction of certain metal species from the aqueous phase is typically accomplished with formation of extractable metal-organic complexes. The solubility of these complexes is much greater in an immiscible organic phase than it is in the aqueous phase. The extractable complex is formed either by interaction with the immiscible organic solvent, or by utilizing a complexing agent solvated in a diluent organic.

What makes solvent extraction the most effective separation method for industrial-scale application is its amenability to finite-stage mass transfer unit operations. The required number of stages can be used in a countercurrent cascade to obtain a desired separation, as long as the separation is technically feasible. Typically, for a given process footprint, a greater throughput can be realized with liquid-liquid extraction than with any other separation methods.

Beyond simple extraction, fractional extraction techniques allow for intricate and specialized separations of solute species. Scrubbing is a technique utilized to remove unwanted species that were physically entrained by the organic phase or have also been complexed and extracted into the organic phase. The scrub solution pulls these species back into the aqueous phase so that they will eventually leave the extraction section with the aqueous phase raffinate stream. Specialized chemical agents in the scrub stream may be required to effect this separation. Stripping is the inverse of extraction and is utilized to pull the target solute back into an aqueous phase. Likewise, other chemical agents in the strip stream may 
be required to effect this separation. In this scheme, the organic phase is perpetually recycled through the system.

Over the years, through exhaustive exploration and study, it has become evident that some chemical agents are best suited for certain functions, such as complexants, or scrubbing, or for stripping. It has become evident that some agents work on certain chemical groups or families; d-shell transition metals, lanthanides, actinides (for multi-oxidation state species, agent effectiveness can depend also on the metal's oxidation state) and, alkalies and alkaline earths. By elucidating the mechanisms of these agents, researchers have exploited and enhanced their utility in nuclear chemistry and process engineering applications.

Integral to the AFCI Program's vision for an optimized closed fuel cycle, irradiated fuel from existing and new operational light water reactors (LWRs) would be processed in a future spent fuel treatment facility (SFTF). The AFCI program is currently evaluating several processing options for the treatment of LWR fuel. In one of the proposed AFCI flowsheets, uranium is removed from the dissolved fuel stream first using the uranium extraction process (UREX), followed by $\mathrm{Cs} / \mathrm{Sr}$ removal from the UREX process raffinate stream. Heavy radiation shielding is required for both of these separation operations due to the $\beta / \gamma$ radiation field. Most of this activity is due to the fission products ${ }^{137} \mathrm{Cs}$ and ${ }^{90} \mathrm{Sr}$ in the dissolved spent fuel, which also account for the majority of the short-term heat load in the repository. These elements have relatively short half lives, 30 and 29 years, respectively, so that the majority of their radioactivity and associated heat decays within a few hundred years. The AFCI program is investigating methods to separate these two elements and manage them in a temporary storage facility until they have decayed sufficiently to dispose of them as low-level waste.

One method of optimizing the processing of cesium and strontium is to minimize the number of separation processes utilized. To this end, separation processes in which cesium and strontium are simultaneously removed from the spent fuel are highly desired. Therefore the purpose of this literature survey was to review technologies for separating cesium and strontium with the goal of identifying technologies that could conceivable be utilized to simultaneously separate cesium and strontium and allow their management as a single product.

\section{LITERATURE SURVEY/REVIEW}

A comprehensive literature review of separation technologies that could be utilized in an LWR treatment facility for simultaneous extraction of $\mathrm{Cs}$ and $\mathrm{Sr}$ was conducted. This effort revealed that potential cesium and strontium separation schemes fall into two categories: 1) chemical agents used in countercurrent liquid-liquid extraction operations, and 2) immobilized chemical agents used in fixed-bed ion exchange columns. Typically, liquid-liquid extraction processes are deployed when a solute(s) is to be separated from solutions with large concentrations of other metals. Ion exchange/extraction chromatography is typically used for more dilute solutions, to collect and concentrate species, when the use of organic solvents is not desired, and when the column media may be part of a final waste form. In the past, ion exchange technology was used in tail-end processes of fuel reprocessing [2]. Although precipitation/co-precipitation processes have been used for industrial-scale radiochemical separations, specific simultaneous removal of cesium and strontium using this separation technology was not feasible, and was therefore not included within the scope of this review. A fairly comprehensive overview of cesium and strontium separation processes was performed by Schulz and Bray in the late 1980's, however, significant developments have been made in separation methods for these elements in the past 15 years [3]. 


\subsection{Ion Exchange/Extraction Chromatography}

Extensive research and development has been performed on the application of ion exchange and extraction chromatography technologies for the separation of cesium and strontium. Most of this work has been directed at the treatment of waste streams with trace levels of contamination. That portion of the research applied toward separating cesium and strontium from acidic media may be applicable to treatment of dissolved spent fuel. Separation of cesium from acidic streams has been demonstrated with many ion exchange and fixed extractant media. Inorganic ion exchange media highly specific for cesium and strontium have been identified, however, effective acid-side separation of strontium by this method has not been widely reported [4]. Because no ion exchange material capable of separating both cesium and strontium from acidic dissolved spent fuel has been identified, a brief summary of some of the work related to individual element separation is given.

Naturally occurring phlogopite $\left(\mathrm{KMg}_{3} \mathrm{AlSi}_{3} \mathrm{O}_{10} \mathrm{~F}(\mathrm{OH})\right)$ mica was modified for selective removal of cesium [5]. Synthetic mica was used to remove strontium [6]. Both of these rather non-selective technologies were developed to utilize the sorbent in the final waste formulation. These media are not amenable to the AFCI cesium/strontium process scheme because species that require separate management from $\mathrm{Cs} / \mathrm{Sr}$ would likely also be adsorbed on these media (such as transuranic elements).

Cesium removal from acidic solutions utilizing transition metal cyanoferrate sorbents has been widely demonstrated $[7,8,9,10]$. Historically, cyanoferrates were used to precipitate cesium from solution because their small particle size and low permeability made application in fixed-bed columns impractical $[7,11]$. Efforts to prepare cyanoferrates as engineered forms proved successful and at least one form of potassium cobalt hexacyanoferrate is commercially available [12]. Much work has been done with metal cyanoferrates for the removal of cesium from nuclear waste streams. Small-scale $(1 \mathrm{cc})$ column tests with simulated JAERI Tokai-Mura site waste were performed [13]. The use of potassium, nickel hexacyanoferrate $\left(\mathrm{KNiFe}(\mathrm{CN})_{6}\right)$ for cesium removal over a $\mathrm{pH}$ range of 1-10 has also been reported [14]. Numerous cyanoferrates with $\mathrm{Cu}, \mathrm{Co}, \mathrm{Ni}$ and $\mathrm{Zn}$ transition metals in polyacrylonitrile (PAN) matricies for the removal of cesium have been developed and tested [15].

There has been a significant amount of work in the development of titanates and silicotitanates for removal of cesium [16-20]. While the majority of research for crystalline silicotitanates (CST) has been with alkaline media, much work has also been done with acidic waste simulants or actual wastes [10, 19]. In alkaline media, cesium and strontium are both sorbed by CST's, however, in liquids containing molar quantities of nitric acid, strontium is not removed by CST. Cesium cannot be easily removed from CST and related exchangers and, therefore, the exchanger becomes part of the final waste form.

Ammonium molybdophosphate (AMP) has also been extensively investigated, and found to be highly effective for the removal of cesium from acidic liquids. [21-24]. Ammonium molybdophosphate becomes soluble in solutions with $\mathrm{pH}>4$, and therefore, is only applicable to acidic solutions. Cesium can be eluted from AMP with concentrated ammonium salt solutions $\left(\mathrm{NH}_{4} \mathrm{NO}_{3}, \mathrm{NH}_{4} \mathrm{Cl}\right.$, etc. $)$ or the cesium and ammonium molybdophosphate complexes can be dissolved in caustic to separate the active exchanger material from an inert binder material, such as PAN. [25]

Other ion exchange materials based on titanium and zirconium phosphate [26], antimony pentoxide, titanium dioxide, and various other metal oxides [27-31], and zirconium monohydrogen phosphate (ZrHP) sorbent embedded with AMP have been developed and tested for the removal of cesium from acidic media [32]. 
Limited testing has shown that polyantimonic acid (PAA) effectively removes strontium from waste solutions containing1-2 $\mathrm{M}$ nitric acid, however, there are a number of drawbacks for using PAA, including low Sr capacity, slow kinetics, and limited selectivity over other alkaline earth elements (e.g. $\mathrm{Mg})[33,34]$.

Several extraction chromatography techniques (where extractants have been fixed on a substrate) have been explored. Horwitz and co-workers at Argonne National Laboratory (ANL) developed a strontium extraction chromatography media that is basically a macrocyclic polyether (crown ether) impregnated in an organic resin and is commercially produced by Eichrom Technologies Inc. as Sr-Resin ${ }^{\text {TM }}$. Bench-scale testing demonstrated that this product performed very well in removal of $\mathrm{Sr}$ from Hanford alkaline-side tank waste [35]. The extractant used in Sr-Resin ${ }^{\mathrm{TM}}$ is the same extractant used in the SREX solvent extraction process, vide infra. However, for the large-scale separation required to meet the AFCI program goals, a process that recycles the organic solvent is preferred over one that generates a large amount of contaminated solid waste.

Rais investigated fixing traditional solvent extractants in a polymer polyvinyl chloride membrane [36]. Small-scale laboratory testing with ${ }^{137} \mathrm{Cs}$ and ${ }^{85} \mathrm{Sr}$ spiked acid-side simulants demonstrated that effective removal of $\mathrm{Cs}$ was obtained with cobalt dicarbollide; however removal of $\mathrm{Sr}$ was poor. Addition of a crown ether did not improve Sr removal. Acceptable removal of $\mathrm{Sr}$ was obtained by adding a polyethylene glycol agent (PEG 400).

\subsection{Solvent Extraction}

Effective acid-side extraction of both cesium and strontium with various extractants dissolved in organic solvents has been demonstrated.

\subsubsection{CCD (Chlorinated Cobalt Dicarbollide)/ PEG (Polyethylene Glycol)}

Rais and Kyrs, and their colleagues at the Nuclear Research Institute in Czechoslovakia, first published the utility of cobalt dicarbollide as a cesium extractant [37]. The Czech researchers determined that strontium could also be extracted with the cesium by adding polyethylene glycol (PEG) to the cobalt dicarbollide dissolved in nitrobenzene [38]. Chlorinated cobalt dicarbollide (CCD) and PEG have good chemical and radiation stability [39]. The Czech scientists later worked with Russian researchers at the Khlopin Radium Institute (KRI) to develop the combined Cs/Sr extraction process for large-scale applications [40]. Russia used this process in a countercurrent solvent extraction process at the Mayak radiochemical plant RT-1 [41]. This process was later used on an industrial-scale to remove cesium and strontium from acidic high-level waste (HLW) at the Mayak UE-35 facility. This process utilized a solvent comprised of chlorinated cobalt dicarbollide, PEG, and an $m$-nitrobenzotrifluoride (MNBTF) diluent. Treatment of over $1000 \mathrm{~m}^{3}$ of Mayak HLW, resulting in recovery of approximately $15 \mathrm{MCi}$ of $\mathrm{Cs} / \mathrm{Sr}$ was achieved [42]. Investigation of the $\mathrm{CCD} / \mathrm{PEG}$ extraction process using alternative diluents has been underway by KRI and the INEEL [43]. A process has been developed and tested that provides a high degree of recovery of $\mathrm{Cs} / \mathrm{Sr}$ from acidic tank waste at the INEEL [44]. Separation efficiencies of $99.992 \%$ and $97.5 \%$ for strontium and cesium, respectively, were achieved in a countercurrent pilot plant test. Currently development efforts are underway to adapt this process, developed for waste treatment, to the separation of cesium and strontium from spent commercial nuclear fuel [45].

Because the very hydrophobic salts of cobalt dicarbollide are completely dissociated in the organic phase, polar aromatic or aliphatic nitrocompound diluents have typically been used in these extraction systems [37]. Although industrial-scale success was demonstrated with first generation nitrobenzene-based 
solvents at Russia's Mayak facility, in the United States the nitrobenzene and nitroaromatic diluents have been deemed unacceptable due to environmental, health, and plant safety issues.

To address these issues, researchers at the Los Alamos National Laboratory (LANL) investigated use of alkyl cobalt dicarbollide/PEG in non-hazardous aromatic hydrocarbon diluents. However, the thrust of this work has been directed at alkaline-side separations [46, 47].

Khlopin Radium Institute and INEEL researchers collaborated on improving the CCD/PEG process to overcome these environmental, health, and plant safety challenges. They included efforts to incorporate actinide extraction into the process to provide a single process capable of decontaminating highly radioactive waste. This new process for the simultaneous extraction of cesium, strontium, and actinides was named the Universal Extraction (UNEX) process [48-50]. Constraints on the solvent led to investigation of fluorinated sulfones as diluents. Testing revealed that phenylpolyfluoroalkyl sulfones are promising diluents with respect to the properties evaluated; these sulfone diluents have good chemical and radiation stability, and are chemically innocuous - and surpass typical PUREX solvent explosion and fire safety indices [51]. In addition, a guanidine carbonate and diethylene triamine pentaacetic acid (DTPA) stripping agent mixture was identified as a satisfactory substitute for the original hydrazine-based stripping agent [52]. The UNEX process has been successfully demonstrated in centrifugal contactors using three different actual radioactive wastes in the U.S. and Russia (with waste volumes up to 100 L) $[52,53]$. It has also been demonstrated for 70 hours with centrifugal contactors in continuous operation by using a simulated waste feed [54].

Current development efforts are focused on the separation of cesium and strontium from the acidic raffinate from the uranium extraction (UREX) process. The solvent composition includes chlorinated cobalt dicarbollide (Cs extractant), nonsubstituted polyethylene glycol (PEG-400) (Sr extractant), all in a phenyltrifluoromethyl sulfone diluent. A guanidine carbonate/DTPA strip solution was used. Viable co-extraction of $\mathrm{Cs}$ and $\mathrm{Sr}$ with this extraction process was demonstrated [55]. Optimization of the solvent composition and development of a process flowsheet is currently underway at the INEEL. Ultimately, validation with actual radioactive reprocessing streams (e.g. UREX raffinate) are planned. Alternative stripping agents that can be recycled and result in significantly less organic mass in the resultant strip product stream are also under investigation [56].

Based on the results discussed in this section, it is anticipated that substitution of the sulfone for the nitrobenzene diluent, along with acceptable stripping agents, will permit approval of the pioneered $\mathrm{CCD} / \mathrm{PEG}$ solvents for use on a production scale, in the United States.

\subsubsection{Crown Ethers}

Application of macrocyclic polyethers, or crown ethers, to extract alkali metals was discovered by Pederson in 1967 [57]. Various crown ethers have been found to be effective for extracting either cesium or strontium from aqueous streams. Early pioneering investigations of crown ethers as extractants for cesium and strontium were performed by Davis at the University of South Carolina and by McDowell at Oak Ridge National Laboratory [58-61].

Researchers at Argonne National Laboratory (ANL) developed a strontium extraction process in the early 1990's based on the use of a di-cyclohexano 18-crown-6 extractant dissolved in 1-octanol [62]. Strontium extraction is highly dependent on the nitric acid concentration in the feed, typically requiring from 3-6 $\mathrm{M}$ for efficient extraction. Stripping the strontium from the solvent is easily accomplished using concentrations of $\leq 0.1 \mathrm{M}$ nitric acid. Modifications to the extractant were made to reduce solubility in the aqueous phase [63]. This process, which utilized 4,4'(5')-di-t-butylcyclohexano 18-crown-6 in 1octanol was called the SREX process for strontium extraction. The SREX process was tested on 
simulated INEEL tank wastes, which contain significant amounts of competing ions, namely, sodium and potassium [64]. The SREX solvent composition was later changed to incorporate tributyl phosphate as a phase modifier in Isopar $\mathrm{L}^{\circledR}$ [65]. Considerations of using the SREX process in combination with the Transuranium Extraction (TRUEX) process, which also uses tributyl phosphate as a phase modifier in Isopar $L^{\circledR}$, led to this change. Extensive tests via laboratory batch contacts and in centrifugal contactors with simulated and actual acidic tank waste and dissolved calcine solutions have been performed at the INEEL [66-70]

Similar research efforts by Filippov and co-workers to develop crown ethers as extractants were also underway in Russia [71]. The Russian researchers utilized the same di-cyclohexano 18-crown-6 extractant as the ANL researchers, but utilized fluorinated alcohols as synergists, to increase extraction distribution coefficients.

Extraction of cesium using crown ethers has been extensively studied, but to date, no efficient process has been proposed [72,73]. Researchers at ANL developed a derivative of dibenzo-18-crown-6 (CSEX) that had good cesium distributions and high selectivity of cesium over sodium, but the extractant molecule was not stable in nitric acid media [74,75]. Russian researchers focused on dibenzo-21-crown-6 extractant molecules, but with limited success [76].

In order to achieve concomitant extraction of cesium and strontium, the CSEX and the SREX extractants were combined into a single solvent by ANL researchers into the combined CSEX-SREX process [77].

Bench-top acid-side batch extraction of ${ }^{137} \mathrm{Cs}$ and ${ }^{85} \mathrm{Sr}$ spiked solutions (dissolved INEEL calcine simulants) were performed with the combined process solvent, comprised of the CSEX dibenzo18-crown-6 Cs extractant, the traditional di-t-butylcyclohexano 18-crown-6 Sr extractant, in an isoparaffinic hydrocarbon diluent with TBP solvent phase modifier [77]. Testing of the CSEX-SREX process was performed with simulated INEEL dissolved calcine solutions in centrifugal contactors by ANL in the mid-1990's [78]. The test was successful, achieving high decontamination factors for cesium and strontium; however, the cesium extractant was very unstable in nitric acid. Repeated attempts to modify the cesium extractant to improve its stability in nitric acid were unsuccessful and no further development of this process was pursued.

Vanura investigated extraction of cesium and strontium by a mixture of cobalt dicarbollide and various crown ether extractants in nitrobenzene diluent. The effects of the different crown variants in the solvent on the extraction of Cs and Sr were demonstrated on the laboratory scale [79].

Crown ethers are stereospecific extractants because they have a cage structure that can be highly selective for the $\mathrm{Cs}^{1+}$ and/or $\mathrm{Sr}^{2+}$ cations. The primary disadvantages of the crown ethers have been chemical and radiolytic instability, tendency for third phase formation, and cost $[1,78]$. At the present time, there does not appear to be a feasible process for simultaneous cesium and strontium separation ready for scale-up and testing on spent nuclear fuel solutions, based solely on crown ether extractants.

\subsubsection{Calixarenes/Calixarene-crown ethers}

In the mid-1980's, Izatt first investigated utilization of calixarenes (cyclic compounds constituted by four phenolic units linked by methylene groups, $p$-tert-butyl-calix[4]arene) for selectively separating cesium from other alkali cations [80,81]. In an effort to find better cesium extractants, a Commission of the European Communities study performed at Cadarache, France, looked at functionalized calixarenes and, particularly, dialkyl calyx[4]arenas-crowns [82-84]. Numerous calixarene-crown extractants were developed, synthesized, and lab-scale tested during this project. It was determined that compounds with a polyethylene glycol chain containing six oxygen atoms were more efficient for cesium extraction and more selective for cesium over sodium than compounds containing five or seven oxygen atoms $[85,86]$. 
Researchers at Oak Ridge National Laboratory successfully developed a Caustic-Side Solvent Extraction (CSSX) process to separate cesium from alkaline waste [87]. This process was recently demonstrated on actual waste solutions, using small-scale centrifugal contactors, at the Savannah River Site [88].

Oak Ridge National Laboratory researchers also investigated various calix[4]arene-crown ethers for potential use on INEEL acidic tank waste [89]. This work demonstrated that these extractants are highly effective at removing cesium from acidic media. This work was initially applied to acidic wastes at the INEEL, but was discontinued before a demonstration could be performed.

Calixarenes appear to be stable in acidic media, however, they are still relatively expensive extractants. The major advantage of calixarenes over other cesium extractants, such as cobalt dicarbollide, is cesium can be easily stripped from the solvent using water or dilute nitric acid solutions. There appears to be very little literature on the application of calixarenes for the extraction of strontium.

Researchers at the INEEL recently proposed looking at a new combined solvent extraction process, in which 4,4'(5')-di-t-butylcyclohexano 18-crown-6 ( $\mathrm{Sr}$ extractant) is combined with various calix[4] arenes in a hydrocarbon diluent and a fluorinated alcohol modifier. Initial laboratory testing at the INEEL has shown that the combined solvent effectively extracts both cesium and strontium from $1 \mathrm{M}$ nitric acid, and both cesium and strontium can be effectively stripped from the solvent with $0.01 \mathrm{M}$ nitric acid [90]. Although this technology appears to be very promising, considerable testing is required to develop combined crown ether/calixarene solvents for separation of $\mathrm{Cs}$ and $\mathrm{Sr}$ from spent nuclear fuel. Optimal extractant compositions in the solvents, which will not become loaded by the relatively large concentrations of $\mathrm{Cs}$ and $\mathrm{Sr}$ in spent fuel, need to be determined. Batch contact testing with UREX raffinate simulants needs to be performed, ultimately leading to countercurrent flowsheet testing with simulated and actual dissolved spent LWR fuel.

\subsubsection{Novel Extractants}

As a result of on-going study of cesium and strontium removal from nuclear processing streams and environmental applications, new and novel Cs/Sr extractants are being developed. Recently Czech and French investigators synthesized extractants in which cobalt dicarbollide and crown ether moieties are covalently bonded; potentially reducing the complexity of the extraction system and requiring a less polar diluent [91]. Testing was performed with several of the synthesized crown-cobalt dicarbollide-bonded extractants in a nitrophenylhexyl ether (NPHE) diluent with ${ }^{137} \mathrm{Cs}$ and ${ }^{85} \mathrm{Sr}$ spiked acidic solutions. This lab-scale testing demonstrated that better selectivities were achieved with the covalently bonded extractants compared to those for their synergistic mixtures.

\section{CONCLUSIONS AND RECOMMENDATIONS}

There has been a tremendous amount of research devoted to separating cesium and strontium from nuclear wastes and spent nuclear fuel solutions. It appears that interest in this area has significantly increased in the last 10-15 years. There are literally dozens of technologies that have been studied and many of them are capable of separating cesium and/or strontium under certain conditions. However, there are only a handful of technologies that have been developed to the stage where they are ready for testing in prototypic equipment and processes. For simultaneous separation of cesium and strontium from acidic media, one must exclude current ion exchange technology. Solvent extraction technologies have been successfully demonstrated for the simultaneous separation of cesium and strontium, namely the $\mathrm{CCD} / \mathrm{PEG}$ process, CSEX/SREX process, and a combined crown ether/calixarene process. 
The CCD/PEG process has been demonstrated on an industrial scale in Russia, using nitrobenzene-based diluents and hydrazine-based stripping agents. Recent developments have produced alternative solutions to replace these hazardous chemicals, for potential use in the U.S. However, the effect that these materials may have on downstream product solidification processes is not presently known. The new diluent for the CCD/PEG process, phenyltrifluoromethyl sulfone, is currently not produced commercially, and is quite expensive. It is highly probable that a manufacturer can be found, provided there is demand for the material in sufficient quantities, and the resulting price would be substantially less. The CCD/PEG is the most mature of the combined cesium/strontium separation processes, and as such, should be considered the reference process for AFCI applications and comparisons with other technologies. There are still significant testing needs with the CCD/PEG process for it to be used in an AFCI application. These needs include optimization of the solvent composition for specific AFCI flowsheets, development of alternative stripping reagents and testing of follow-on solidification processes, small-scale pilot plant testing in centrifugal contactors using simulated and actual feeds, and engineering-scale pilot plant testing using simulated and actual feeds.

Stability of the CSEX crown ether in nitric acid precludes its use in an industrial process at this time. Without further development, the CSEX/SREX process is not a feasible option for AFCI applications. Any additional research on the CSEX/SREX process should be focused on improving stability of the cesium extractant in nitric acid.

The combined crown ether/calixarene process, being developed at the INEEL, has shown much promise. The extractants and solvent components are all commercially available, although still rather expensive. The process is more conventional for the U.S. than the CCD/PEG process as it uses a hydrocarbon-based solvent and stripping is performed with dilute nitric acid. While much work has been performed with the extractants for this process, it has all been done in separate solvent systems, and not in a combined extractant flowsheet. There is a substantial amount of laboratory testing, flowsheet development and testing of a countercurrent process that must be done to increase the maturity of this process, before it can be considered for implementation for spent fuel treatment.

\section{REFERENCES}

1. G. R. Choppin, M. K. Khankhasayev, H. S. Plendl, Chemical Separations in Nuclear Waste Management, DOE/EM-0591, Battelle Press, Columbus OH, 2002.

2. J. T. Long, Engineering for Nuclear Fuel Reprocessing, American Nuclear Society, 1978.

3. W. W. Schulz, L. A. Bray, Solvent Extraction recovery of Byproduct ${ }^{137} \mathrm{Cs}$ and ${ }^{90} \mathrm{Sr}$ from $\mathrm{HNO}_{3}$ Solutions-A Technology Review and Assessment, Separation Science and Technology, 22 (2\&3), 191-214, 1987.

4. A. Clearfield, Inorganic Ion Exchangers, Past, Present, and Future, Solvent Extraction Ion Exchange, 18(4), 655-678, 2000.

5. S. Komarneni, R. Roy, A Cesium Selective Ion Sieve made by Topotactic Leaching of Phlogopite Mica, Science, 239, 1286, 1988.

6. W. J. Paulus, S. Komarneni, and R. Roy, Bulk Synthesis and Selective Exchange of Strontium Ions in $\mathrm{Na}_{4} \mathrm{Mg}_{6} \mathrm{Al}_{4} \mathrm{Si}_{4} \mathrm{O}_{20} \mathrm{~F}_{4}$ Mica, Nature, 357, 571, 1992. 
7. P. A. Hass, A Review of Information on Ferrocyanide Solids for Removal of Cesium from Solutions, Separation Science and Technology, 28(17-18), 2479-2506, 1993.

8. V. V. Milyutin, et al., Sorption Technology for Removal of Cs-137 from Solutions of Spent Nuclear Fuel Reprocessing, Radiochemistry, 38(1), 85-87, 1995.

9. H. Mimura, J. Lehto, R. Harjula, Selective Removal of Cesium from Simulated High-Level Liquid Wastes by Insoluble Ferrocyanides, Journal of Nuclear Science and Technology, 28(17-18), 2479-2506, 1993.

10. T. A. Todd, et al., Evaluation and Testing of Inorganic Ion Exchange Sorbents for the Removal of Cesium-137 from Idaho Chemical Processing Plant Acidic Tank Waste, Separation Science and Technology, 36(5\&6), 999-1016, 2001.

11. V. Kourim, J. Rais, B. Million, Exchange properties of Complex Cyanides-I: Ion Exchange of Cesium on Ferrocyanides, J. Inorg. Nucl. Chem., 26, 1111-1115, 1964.

12. R. Harjula, J. Lehto, L. Saarinen, A. Paajanen, and E. Tusa, CsTreat- Superior Ion Exchange Material for the Removal of Radioactive Cesium from Nuclear Waste Effluents: Present Experience in Plant Operation and Future Potential, Proceedings of Waste Management '96, Tucson, Arizona, February 1996.

13. R. Harjula, et al., Development of a Selective Cesium and Strontium Removal System for the JAERI Tokai-Mura Site- Laboratory Tests, Proceedings of Waste Management '00, Tucson, Arizona, March 2000.

14. H. Mimura, J. Lehto, and R. Harjula, Ion Exchange of Cesium on Potassium Nickel Hexacyanoferrate (II)s, J. Nucl. Sci. and Tech., 34(5), 484-489, 1997.

15. F. Sebesta, Composite Sorbents of Inorganic Ion-Exchangers and Polyacrylonitrile Binding Matrix. I. Methods of Modification of Properties of Inorganic Ion-Exchangers for Application in Column Packed Beds, Journal of Radioanalytical and Nuclear Chemistry, 220(1), 77-88, 1997.

16. R. G. Anthony, R. G. Dosch, D. Gu, and C. V. Philip, Use of Silicotitanates for Removing Cesium and Strontium from Defense Waste, Ind. Eng. Chem. Res., 33, 2702-2705, 1994.

17. J. E. Miller, and N. E. Brown, Development and Properties of Crystalline Silicotitanate (CST) Ion Exchangers for Radioactive Waste Applications, SAND97-0771, April 1997.

18. Z. Zheng, et al., Ion Exchange of Group I Metals by Hydrous Crystalline Silicotitanates, Ind. Eng. Chem. Res., 35, 4246-4256, 1996.

19. N. R. Mann and T. A. Todd, Removal of Cesium from Acidic Radioactive Tank Waste Using IONSIV IE-911, accepted for publication in Separation Science and Technology, 2004.

20. D. D. Walker, Cesium Sorption/Desorption Experiments with IONSIV IE-911 in Radioactive Waste, WSRC-TR-2000-00362, December 2000. 
21. J. John, F. Sebasta, A. Motl, Application of New Inorganic-Organic Composite Absorbers with Polyacrylonitrile Binding Matrix for Separation of Radionuclides from Liquid Radioactive Wastes, Chemical Separation Technologies and Related Methods of Nuclear Waste Management, G. R. Choppin, M. K. Khankhasayev (eds), Kluwer Academic Publishers, Dordrecht, 1999.

22. F. Sebesta, J. John, and A. Motl, Phase II Report on the Evaluation of Polyacrylonitrile (PAN) as a Binding Polymer for Absorbers Used to Treat Liquid Radioactive Wastes, SAND96-1088, 1996.

23. T. A. Todd, N. R. Mann, T. J. Tranter, F. Sebesta, J. John and A. Motl, Cesium Sorption from Concentrated Acidic Tank Wastes Using Ammonium Molybdophosphate-Polyacrylonitrile Composite Sorbents, Journal of Radioanalytical and Nuclear Chemistry, 254(1), 47-52, 2002.

24. T. J. Tranter, et al., Evaluation and Testing of Ammonium Molybdophosphate-Polyacrylonitrile (AMP-PAN) as a Cesium Selective Sorbent for the Removal of Cesium-137 from INTEC Acidic Waste, Advances in Environmental Research, 6, 107-121, 2002.

25. K. N. Brewer, et al., AMP-PAN Column Testing with Actual INEEL High Activity Wastes, Czech Journal of Physics, 49 S-1, 959-964, 1999.

26. A. I. Bortun, et al., Cs-137 Sorption on Granular Inorganic Ion-Exchangers based on Titanium and Zirconium Hydroxophosphates, Journal of Radioanalytical and Nuclear Chemistry, 174(2), 279-289, 1993.

27. T. Moller, A. Clearfield, R. Harjula, Preparation of hydrous mixed metal oxides of Sb, Nb, Si, Ti and $\mathrm{W}$ with a pyrochlore structure and exchange of radioactive cesium and strontium ions into the materials, Microporous and Mesoporous Materials, 54(1-2), 187-199, 2002.

28. J. Narbutt, A. Bilewicz, B. Bartos, Composite Ion-Exchangers - Prospective Nuclear Applications, Journal of Radioanalytical and Nuclear Chemistry, 183(1), 27-32 1994.

29. Yamazaki, Inoue, Airano, Studies of Hydrous Silicon-Titanium (IV) Oxide Ion Exchanger. III. The Rate of the Isotopic Exchange of $\mathrm{Na}(+)$ and $\mathrm{Cs}(+)$ Ions Between the Exchanger in the Relevant Ionic Form and Aqueous Solutions, Solvent Extraction Ion Exchange, 13, 157, 1995.

30. A. Clearfield, A. I. Bortun, L. N. Bortun, Cahill, Synthesis and Characterization of a Novel Layered Sodium Titanium Silicate Na2TiSi2O 7 - 2H2O, Solvent Extraction and Ion Exchange, 15(2), 285, 1997.

31. Puziy, Cesium and Strontium Exchange by the Framework Potassium Titanium Silicate K3Ti4O4(SiO4)3.4H2O, Journal of Radioanalytical and Nuclear Chemistry, 237(1-2), 73-79, 1998.

32. J. L. Collins, K. K. Anderson, Development of Spheroidal Inorganic Sorbents for Treatment of Acidic Salt-Bearing Liquid Waste, ORNL/TM-2000/367, 2000.

33. L. Baetsle, D. Huys, and P. Speeckaert, Separation of Cs-137 and Sr-90 from Highly Radioactive Fission Product Solutions, BLG-487, 1973. 
34. W. H. Min and S. Zhaoxiang, Recovery of Cesium and Strontium from Acidic HLW from Power Reactors with Inorganic Ion Exchangers, proceedings of Waste Management '92, Tucson, Arizona, 1992.

35. G. J. Lumetta et al., Preliminary Evaluation of Chromatographic Techniques for the Separation of Radionuclides from High-Level Radioactive Waste, Solvent Extraction and Ion Exchange, 11(4), 663-682, 1993.

36. J. Rais, C. V. Mason, K. D. Abey, Use of PVC Plasticized Membranes for Uptake of Radioactive Cesium and Strontium, Separation Science and Technology, 32(5), 951-969, 1997.

37. J. Rais, P. Selucky, M. Kyrś, Extraction of Alkali-Metals into Nitrobenzene in Presence of Univalent Polyhedral Borate Anions, Journal of Inorganic Nuclear Chemistry, 38, 1376, 1976.

38. M. Kyrś, P. Selucky, A Rapid Separation of Sr from Ca by Solvent Extraction with Dicarbollides in the Presence of EDTA and Polyethylene Glycols, Journal of Radioanalytical and Nuclear Chemistry Ar., 174(1), 153-165, 1993.

39. J. Rais, J. Plesek, P. Selucky, Extraction of Cesium with Derivatives of Carborane into Nitrobenzene, Journal of Radioanalytical and Nuclear Chemistry Ar., 148(2), 349-357, 1991.

40. B. Y. Galkin, V. M. Esimantovskiy, L. N. Lazarev, R. I. Lyubtsev, V. N. Romanovsky, M. Kyrś, J. Rais, Proceedings of ISEC-88, Vol. 4, Moscow, Nauka, 215, 1988.

41. E. G. Dzekun et al., Industrial-Scale Plant for HLW Partitioning in Russia, proceedings of SPECTRUM'96, American Nuclear Society, LaGrange Park IL, 2138, 1996.

42. V. N. Romanovsky, U.S.-Russian Cooperative Program in Research and Development of Chemical Separation Technologies, Chemical Separations in Nuclear Waste Management, G. R. Choppin, M. K. Khankhasayev, H. S. Plendl (eds), DOE/EM-0591, Battelle Press, Columbus OH, 2002.

43. J. D. Law, et al., Flowsheet Testing of the Cobalt Dicarbollide Solvent Extraction Process for the Partitioning of ${ }^{137} \mathrm{Cs}$ and ${ }^{90} \mathrm{Sr}$ from Actual ICPP Waste Using Centrifugal Contactors in a Shielded Cell Facility, INEL-96/0192, July 1996.

44. R. S. Herbst, et al., Development and Testing of a Cobalt Dicarbollide Based Solvent Extraction Process for the Separation of Cesium and Strontium From of Acidic Tank Waste, Separation Science and Technology, 37(8), 1807-1831, 2002.

45. J. D. Law, R. S. Herbst, D. R. Peterman, R. D. Tillotson, T. A. Todd, Development of a Cobalt Dicarbollide/Polyethylene Glycol Solvent Extraction Process for Separation of Cesium and Strontium to Support Advanced Aqueous Reprocessing, Nuclear Technology, in press, 2004.

46. R. M. Miller (Chamberlin), et al., Extraction of Cesium and Strontium into Hydrocarbon Solvents using Tetra-C-Alkyl Cobalt Dicarbollide, Solvent Extraction and Ion Exchange, 13(5), 831-827, 1995. 
47. R. M. Chamberlin, K. D. Abney, Strontium and Cesium Extraction into Hydrocarbons using Alkyl Cobalt Dicarbollide and Polyethylene Glycols, Journal of Radioanalytical and Nuclear Chemistry, 240(2), 547-553, 1999.

48. T. A. Todd, et al., Development of a Universal Cobalt Dicarbollide Solvent for the Removal of Actinides, Cesium and Strontium from Acidic Wastes, proceedings of the International Solvent Extraction Conference ISEC'99, Barcelona, Spain, 1345-1349, 1999.

49. V. N. Romanovskiy, et al., The Universal Extraction (UNEX) Process I. Development of the UNEX Process Solvent for the Separation of Cesium, Strontium, and the Actinides from Acidic Radioactive Waste, Solvent Extraction and Ion Exchange, 19(1), 1-21, 2001.

50. J. D. Law, et al, The Universal Extraction (UNEX) Process II. Flowsheet Development and Demonstration of the UNEX Process for the Separation of Cesium, Strontium, and Actinides from Actual Acidic Radioactive Waste, Solvent Extraction and Ion Exchange, 19(1), 23-36, 2001.

51. T. A. Todd, et al., Development and Characterization of a Universal Solvent Mixture for the Separation of Cesium, Strontium, Actinides and Rare Earth Elements from Acidic Radioactive Waste, proceedings of the International Solvent Extraction Conference ISEC' 2002, Cape Town, South Africa, 1216-1221, 2002.

52. R. S. Herbst, et al., "Development of the Universal Extraction (UNEX) Process for the Simultaneous Recovery of Cesium, Strontium and Actinides from Acidic Radioactive Wastes," Separation Science and Technology, 38(12\&13), 2685-2708, (2003).

53. Personal Communication, V. N. Romanovskiy, April 2002.

54. J. D. Law, et al., Extended Flowsheet Testing of the Universal Extraction (UNEX) Process for the Simultaneous Separation of Cesium, Strontium and Actinides from Acidic Waste, proceedings of the International Solvent Extraction Conference ISEC' 2002, Cape Town, South Africa, 12291234, 2002.

55. J. D. Law, et al., Development of a Cobalt Dicarbollide/Polyethylene Glycol Solvent Extraction Process for Separation of Cesium and Strontium to Support Advanced Aqueous Reprocessing, proceedings of Global 2003, New Orleans, LA, 2003.

56. V. N. Romanovskiy, et al. Regenerable Stripping Reagents for High-Level Waste Reprocessing, proceedings of Global 2003, New Orleans, LA, 2003.

57. C. J. Pederson, The discovery of crown ethers, Science, 241, 536, 1988.

58. I. H. Gerow, M. W. Davis, Jr., The Use of 24-crown-8's in the Solvent Extraction of Cesium Nitrate and Strontium Nitrate, Separation Science and Technology, 14(5), 395-414, 1979.

59. I. H. Gerow, G. E. Smith, and M. W. Davis, Extraction of Cesium $(+1)$ and Strontium $(+2)$ from Nitric Acid Solution using Macrocyclic Polyethers, Separation Science and Technology, 16(5), 519-548, 1981. 
60. W. F. Kinard, W. J. McDowell, and R. R. Shoun, Studies of the size-selective extraction of alkali metal ions by the synergistic extraction system, crown ether-di(2-ethylhexyl) phosphoric acidbenzene, Separation Science and Technology, 15, 1013, 1980.

61. W. J. McDowell, Crown Ethers as Solvent Extraction Reagents: Where do we Stand?, Separation Science and Technology, 23, 1251-1268, 1988.

62. E. P. Horwitz, M. L. Dietz, D. E. Fisher, Extraction of Strontium from Nitric Acid Solutions Using Dicyclohexano-18-Crown-6 and its Derivatives, Solvent Extraction and Ion Exchange, 8(4\&5), 557-572, 1990.

63. E. P. Horwitz, M. L. Dietz, D. E. Fisher, SREX: A New Process for the Extraction and Recovery of Strontium form Acidic Nuclear Waste Streams, Solvent Extraction and Ion Exchange, 9(1), $1-25,1991$.

64. D. J. Wood, T. J. Tranter, and T. A. Todd, Effect of the Interference of Alkali and Alkaline Earth Metal Ions on the Extraction of ${ }^{90} \mathrm{Sr}$ from Acidic Nuclear Waste Solutions by 18 -Crown-6 Derivatives in 1-Octanol, Solvent Extraction and Ion Exchange, 13(5), 829-844, 1995.

65. M. L. Dietz, E. P. Horwitz, and R. D. Rogers, Extraction of Strontium from Acidic Nitrate Media using a Modified PUREX Solvent, Solvent Extraction and Ion Exchange, 13(1), 1-17, 1995.

66. D. J. Wood, J. D. Law, and P.A. Tullock, Extraction of Lead and Strontium from Hazardous Waste Streams by Solvent Extraction with 4', 4',(5')-Di-(T-butylcyclohexano)-18-Crown-6, Solvent Extraction and Ion Exchange, 15(1), 65-78, 1997.

67. J. D. Law, D. J. Wood, and R. S. Herbst, Development and Testing of SREX Flowsheets for Treatment of Idaho Chemical Processing Plant Sodium-Bearing Waste using Centrifugal Contactors, Separation Science and Technology, 32(1-4), 223-240, 1997.

68. D. J. Wood, et al., "Development of the SREX Process for the Treatment of ICPP Liquid Wastes," INEEL/EXT-97-00831, December 1997.

69. D. J. Wood, J. D. Law and T. A. Todd, Demonstration of the SREX Process for the Treatment of Actual High Activity Waste at the INEEL Using Centrifugal Contactors, Science and Technology for Disposal of Radioactive Tank Waste, W. W. Schulz and N. J. Lombardo editors, Plenum Publishing Co., NY, pp. 255-268 1998.

70. J. D. Law, D. J. Wood, and T. A. Todd, Development of a SREX Flowsheet for the Treatment of INEEL Dissolved Calcine using Centrifugal Contactors, ISBN: 0-7918-1966-3, Proceedings from the $7^{\text {th }}$ International Conference on Radioactive Waste Management and Environmental Remediation (ICEM '99), Nagoya, Japan, October 1999.

71. E. A. Filippov, et al. Extraction of Alkaline Earth Metals from Nitric Acid Solutions by the Crown Ether Dicyclohexyl-18-crown-6, Radiochemistry, 24(2), 214-216, 1982.

72. E. Blasius and K. H. Niles, The Removal of Cesium from Medium-Active Waste Solutions I. Evaluation of Crown-Ethers and Special Crown Ether Adducts in the Solvent Extraction of Cesium, Radiochim Acta, 35(3), 173-182, 1984. 
73. J. W. McDowell and G. N. Case, Selective Extraction of Cesium from Acidic Nitrate Solutions with didodecylnaphthalenesulfonic acid synergized with bis(tert-butylbenzo)-21-crown-7, Anal. Chem., 64, 3013, 1992.

74. M. L. Dietz, et al., Extraction of Cesium from Acidic Nitrate Media Using Macrocyclic Polyethers: The Role of Organic Phase Water, Solvent Extraction and Ion Exchange, 14(1), 1-12, 1996.

75. M. L. Dietz, et al., Substituent Effects in the Extraction of Cesium from Acidic Nitrate Media with Macrocyclic Polyethers, Solvent Extraction and Ion Exchange, 14(3), 357-384, 1996.

76. E. A. Filippov, et al., Application of Crown ethers and Ferrocyanide-Based Inorganic Material for Cesium and Strontium Recovery from High-Level Wastes, proceedings of Waste Management '92, Tucson, Arizona, 1992.

77. E. P. Horwitz, M. L. Dietz, M. P. Jensen, proceedings of the International Solvent Extraction Conference (ISEC'96), Melbourne, Australia, Vol. 2, 1285, 1996.

78. E. P. Horwitz, W. W. Schulz, Solvent Extraction in the Treatment of Acidic High-Level Liquid Waste: Where Do We Stand? Metal-Ion Separation and Preconcentration: Progress and Opportunities, A. H. Bond, M. L. Dietz, R. D. Rogers (eds), ACS Symposium Series 716, Washington D.C., 1999.

79. P. Van̆ura, The Extraction of Some Dicarbollylcobaltate Crown Extraction Systems, Journal of Radioanalytical and Nuclear Chemistry, 228(1-2), 43-46, 1998.

80. R. M. Izatt, et al., Selective $\mathrm{M}^{+}-\mathrm{H}^{+}$Coupled Transport Through a Liquid Membrane by Macrocyclic Calixarene Ligands, Journal of American Chemical Society, 105, 1782, 1983.

81. S. R. Izatt, et al., Cation Transport from Multiple Alkali Cation Mixtures using a Liquid Membrane System containing a Series of Calixarene Carriers, Journal of American Chemical Society, 107, 63, 1985.

82. R. Ungaro, et al., Agnew. Chem. Int. Ed. Engl., 33(14), 1506, 1994.

83. Z. Asfari, et al., Anal. Chem., 67, 3133, 1995.

84. J. F. Dozol, et al., Extraction of Strontium and Cesium by Dicarbollides, Crown Ethers and Functionalized Calixarenes, Journal of Inclusion Phenomena and Macrocyclic Chemistry, 38, $1-22,2000$.

85. J. F. Dozol, et al., A Solution for Cesium Removal from High-Salinity Acidic or Alkaline Liquid Waste: The Crown Calix[4]arenes, Separation Science and Technology, 34(6\&7), 877-909, 1999.

86. C. Hill, et al., J. Incl. Phenom., 19, 399, 1994. 
87. P. V. Bonnesen, L. H. Delmau, B. A. Moyer, and R. A. Leonard, A Robust Alkaline-side CSEX Solvent Suitable for Removing Cesium from Savannah River High Level Waste, Solvent Extraction and Ion Exchange, 18 (6), 1079-1108, 2000.

88. M. A. Norato, et al., Demonstration of the Caustic-Side Solvent Extraction Process for Removing ${ }^{137}$ Cs from High-Level Waste at Savannah River Site, Separation Science and Technology, 38(12\&13), 2647-2666, 2003.

89. P. V. Bonnesen, et al., Development of Process Chemistry for the Removal of Cesium from Acidic Nuclear Waste by Calix[4]arene-crown-6 Ethers, in ACS SYMPOSIUM SERIES 757, Calixarenes for Separations, G. J. Lumetta, R. D. Rogers, A. S. Gopalan (eds), American Chemical Society, Washington, DC, 2000.

90. D. H. Meikrantz, et al., U.S. Patent Application, Serial \# 10/808,039, March 2004.

91. B. Grüner, J. F. Dozol, et al., Crown Ether Substituted Cobalta Bis(Dicarbollide) Ions as Selective Extraction Agents for Removal of $\mathrm{Cs}^{+}$and $\mathrm{Cs}^{2+}$ from Nuclear Waste, New Journal of Chemistry, 26, 867-875, 2002. 